OPEN ACCESS

Edited by:

Rob Harcourt,

Macquarie University, Australia

Reviewed by:

Lars Boehme,

University of St Andrews, UK

Rebecca Ruth McIntosh,

Phillip Island Nature Parks, Australia

${ }^{*}$ Correspondence:

Fredrik Christiansen

f.christiansen@murdoch.edu.au

Specialty section

This article was submitted to

Marine Megafauna,

a section of the journa

Frontiers in Marine Science

Received: 30 September 2016 Accepted: 13 December 2016 Published: 26 December 2016

Citation:

Christiansen F, Rojano-Doñate L, Madsen PT and Bejder L (2016) Noise Levels of Multi-Rotor Unmanned Aerial Vehicles with Implications for Potential

Underwater Impacts on Marine

Mammals. Front. Mar. Sci. 3:277.

doi: 10.3389/fmars.2016.00277

\section{Noise Levels of Multi-Rotor Unmanned Aerial Vehicles with Implications for Potential Underwater Impacts on Marine Mammals}

\author{
Fredrik Christiansen ${ }^{1 *}$, Laia Rojano-Doñate ${ }^{2}$, Peter T. Madsen ${ }^{1,2}$ and Lars Bejder ${ }^{1}$ \\ ${ }^{1}$ Cetacean Research Unit, School of Veterinary and Life Sciences, Murdoch University, Murdoch, WA, Australia, \\ ${ }^{2}$ Zoophysiology, Department of Bioscience, Aarhus University, Aarhus, Denmark
}

Despite the rapid increase in the use of unmanned aerial vehicles (UAVs) in marine mammal research, knowledge of the effects of UAVs on study animals is very limited. We recorded the in-air and in-water noise from two commonly used multi-rotor UAVs, the SwellPro Splashdrone and the DJI Inspire 1 Pro, to assess the potential for negative noise effects of UAV use. The Splashdrone and Inspire UAVs produced broad-band in-air source levels of $80 \mathrm{~dB}$ re $20 \mu \mathrm{Pa}$ and $81 \mathrm{~dB}$ re $20 \mu \mathrm{Pa}$ (rms), with fundamental frequencies centered at $60 \mathrm{~Hz}$ and $150 \mathrm{~Hz}$. The noise of the UAVs coupled poorly into the water, and could only be quantified above background noise of the recording sites at $1 \mathrm{~m}$ depth when flying at altitudes of 5 and $10 \mathrm{~m}$, resulting in broad-band received levels around $95 \mathrm{~dB}$ re $\mu \mathrm{Pa}$ rms for the Splashdrone and around $101 \mathrm{~dB}$ re $\mu \mathrm{Pa}$ rms for the Inspire. The third octave levels of the underwater UAV noise profiles are (i) close to ambient noise levels in many shallow water habitats, (ii) largely below the hearing thresholds at low frequencies of toothed whales, but (iii) likely above the hearing thresholds of baleen whales and pinnipeds. So while UAV noise may be heard by some marine mammals underwater, it is implied that the underwater noise effect is small, even for animals close to the water surface. Our findings will be valuable for wildlife managers and regulators when issuing permits and setting guidelines for UAV operations. Further, our experimental setup can be used by others to evaluate noise effects of larger sized UAVs on marine mammals.

Keywords: anthropogenic disturbance, drones, environmental impact assessment, noise exposure, unmanned aerial systems

\section{INTRODUCTION}

The use of unmanned aerial vehicles (UAVs) is increasing rapidly (Teal Group Corporation, 2011). With UAVs offering a safe, inexpensive and user-friendly alternative to conventional aircrafts, UAVs are becoming increasingly popular as a tool in wildlife research and monitoring (Jones et al., 2006; Koh and Wich, 2012; Ogden, 2013; Nowacek et al., 2016). The application of UAVs in wildlife science includes optical surveying and observation of animals (both terrestrial and marine), autonomous wildlife telemetry tracking, and habitat mapping and monitoring (for a review of research areas and species, see Anderson and Gaston, 2013; Chabot and Bird, 2015; Linchant et al., 2015). In the field of marine mammal research, UAVs have been used for monitoring the 
occurrence of animals (Jones et al., 2006; Brooke et al., 2015; Goebel et al., 2015; Moreland et al., 2015), abundance estimations (Hodgson et al., 2013; Sweeney et al., 2016), photo ID (Koski et al., 2015; Pomeroy et al., 2015), photogrammetry (Durban et al., 2015; Goebel et al., 2015; Pomeroy et al., 2015; Christiansen et al., 2016) and collection of breath samples (exhaled breath condensate) to monitor disease (Acevedo-Whitehouse et al., 2010). Some of these applications require UAVs to fly at close range $(<10 \mathrm{~m})$ above the study animals, which increases the risk of disturbance from the noise produced by UAVs.

Many marine mammals critically rely on sound and hearing for orientation, foraging, communication and for threat identification and warning (Tyack, 1998). Because of its importance, marine mammals are susceptible to noise produced by boats and shipping (Jensen et al., 2009; Rolland et al., 2012; Hermannsen et al., 2014), offshore wind farms (Carstensen et al., 2006; Madsen et al., 2006), seismic exploration (Gordon et al., 2003; Pirotta et al., 2014) and military sonar (Miller et al., 2000; Goldbogen et al., 2013). Effects from anthropogenic noise on marine mammals include behavioral changes (e.g., avoidance behavior), physiological effects (e.g., stress and hearing impairment), masking of communication and echolocation signals and changes in vocalizations (for reviews see Richardson et al., 1995; NRC, 2005; Nowacek et al., 2007; Tougaard et al., 2015). Hence the noise emitted from UAVs has the potential to negatively affect marine mammals underwater, provided that the levels are both high enough to evoke a response and above both the hearing thresholds of exposed animals and the prevailing ambient noise level in the study area.

Smith et al. (2016) provides a review of measured effects of UAVs on marine mammals and identified that the two potential sources of disturbance are the visual cues from the UAV (including its shadow) and the noise emitted by the UAV. Impact studies of UAVs on marine mammals and other taxa has identified both the vertical and horizontal distance of the UAV as important factors influencing the response of animals (Goebel et al., 2015; Pomeroy et al., 2015; Vas et al., 2015; Smith et al., 2016). The noise level of the UAV in the context of the prevailing ambient noise in the research area will also play an important role in the impact assessment of UAVs (Goebel et al., 2015; Pomeroy et al., 2015). In an attempt to measure the effect of UAVs on Antarctic wildlife, Goebel et al. (2015) measured the noise levels produced by a multi-rotor UAV (the APH-22 hexacopter) when hovering at various altitudes (between 0 and $90 \mathrm{~m}$ ) and compared the measured noise levels to background levels from a chinstrap penguin (Pygoscelis antarctica) colony. They found that during typical field conditions the noise of the UAV was masked by the background ambient noise of the colony. However, while the noise impact of UAVs might be low in a noisy penguin colony, effects might be higher for animals residing in more quiet terrestrial habitats or underwater. UAVs can elicit behavioral responses in pinnipeds on land, ranging from elevated alertness levels to animals fleeing into the water (Pomeroy et al., 2015; Smith et al., 2016). Still, no study to date has investigated the potential noise effect of UAVs on marine mammals underwater.

This study quantifies the levels of noise in-air and in water produced by UAVs when flown at various altitudes. We developed a simple experimental setup involving an underwater recorder, a SoundTrap, a single in-air microphone and two commonly used UAVs, the SwellPro Splashdrone and the DJI Inspire 1 Pro. We show that the underwater noise levels produced by the two UAVs were low, below or close to the ambient noise levels and below the hearing thresholds of most marine mammals, and hence should have little effect on marine mammals underwater. With UAVs being increasingly used in wildlife research, this study informs an important gap in knowledge of UAV effects on marine mammals, and also provides a simple experimental setup that can be used by other researchers to evaluate noise effects of larger sized UAVs on marine mammals.

\section{METHODOLOGY}

\section{Experimental Setup}

Two types of multi-rotor (quadcopter) UAVs were used for the noise exposure experiment: the SwellPro Splashdrone $(50 \mathrm{~cm}$ diameter, $2.3 \mathrm{~kg}$, carbon fiber propellers, http://www.swellpro. com, Figure 1B), and the DJI Inspire 1 Pro (56 cm diameter, 3.4 $\mathrm{kg}$, plastic propellers, http://www.dji.com, Figure 1C). The two UAVs were operated under a Remotely Piloted Aircraft System License and two UAV Operator Certificates, in accordance with regulations by the Australian Civil Aviation Safety Authority (CASA).

The experimental setup consisted of a calibrated SoundTrap (Ocean Instruments New Zealand) positioned at $1 \mathrm{~m}$ depth (Figure 1). With the motivation of this study coming from a research project measuring the body condition of baleen whales using photogrammetry of whales at the surface (Christiansen et al., 2016), the depth of the SoundTrap was chosen to represent the receiving part of the auditory system of a logging baleen whale (a whale resting motionless at the surface) at $1 \mathrm{~m}$ depth, assuming that submerged marine mammals are further from the surface and hence will receive less noise than when logging. The SoundTrap sampled at $576 \mathrm{kHz}$ (flat $( \pm 2 \mathrm{~dB}$ ) frequency response from 0.02 to $100 \mathrm{kHz}$ ), 16 bit, and had a clip level of $173 \mathrm{~dB}$ re $1 \mu \mathrm{Pa}$. The SoundTrap was calibrated with a GRAS pistonphone and a custom made coupler. The SoundTrap was attached to a rope, which was kept vertical by a weight attached at the bottom and a $200 \mathrm{~mm}$ floating buoy at the top (Figure 1).

The noise exposure experiment for the Splashdrone was carried out in the southern end of Exmouth Gulf, Western Australia $\left(22.31027^{\circ} \mathrm{S}, 114.24062^{\circ} \mathrm{E}\right)$, about $6 \mathrm{~km}$ from land, on 18 August 2015. The water depth was $10 \mathrm{~m}$, with sandy bottom substrate. The experiment for the Inspire was conducted inside Augusta boat harbor, Western Australia (34.35280 S, $115.16811^{\circ} \mathrm{E}$ ) on 30 July 2016. The water depth was $6 \mathrm{~m}$, with rocky bottom substrate. The wind speed during both trials was $<15$ knots. Logistic constraints prevented the two experiments to be carried out at the same time and location. While the difference between sites did influence the ambient noise levels recorded, it is unlikely to have affected the measured UAV noise levels due the signal noise criterion used for inclusion of data. We therefore also compared the UAV noise levels to the ambient noise levels from 


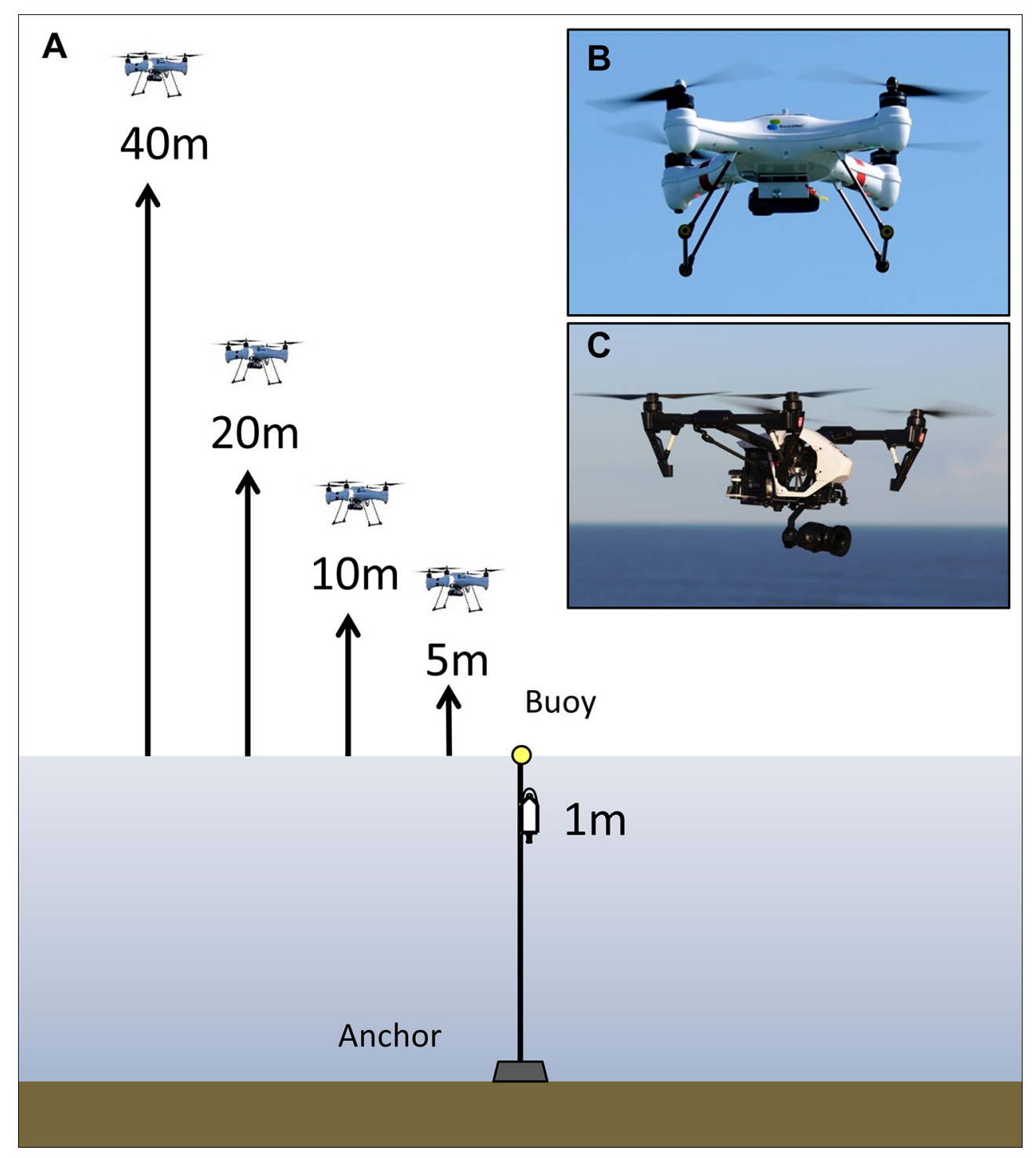

FIGURE 1 | (A) Experimental setup of the UAV noise exposure study. The UAVs were hovering at fixed altitudes above the acoustic array at the heights indicated in the figure. The same trial was also carried out above a microphone placed on land. (B) The SwellPro Splashdrone and (C) DJI Inspire 1 Pro used in the experiment. Note: figure is not drawn to scale.

a suite of different habitats (Baltic Sea, Scotian Shelf, Exmouth Gulf and Koombana Bay off Bunbury, Western Australia) where marine mammals are known to reside.

During the trials, the UAVs hovered at fixed altitudes of 5, 10, 20 , and $40 \mathrm{~m}$ above the acoustic recorder (Figure 1). The UAVs hovered at each altitude for $20 \mathrm{~s}$, and three replicate recordings were carried out at each altitude. To estimate the source levels of the UAVs in-air, we used an Olympus LS-100 multi-track linear PCM recorder sampling at $96.0 \mathrm{kHz}, 16$ bit, having a clip level of $123 \mathrm{~dB}$ re $20 \mu \mathrm{Pa}$ as calibrated relative to a GRAS $1 / 4$ inch microphone in an anechoic room. The recorder was positioned on land $3 \mathrm{~m}$ above ground, and the same UAV trial was repeated with the same number of replicates (three flights at each of 5, 10, 20 , and $40 \mathrm{~m}$ altitude above the recorder).
To prevent potential negative impacts of the UAVs on the local wildlife (i.e., marine mammals, sea turtles and sea birds), one observer visually scanned the experimental site $5 \mathrm{~min}$ before and also during each trial, to ensure that no wildlife was in the vicinity.

\section{Analysis}

The different recordings were identified via a pre-recording synchronization of the SoundTraps/Olympus recorder, the UAV and a GoPro camera on the head of the UAV operator. Initial acoustic analyses were subsequently performed by visual inspection of the in-air noise in spectrograms (settings: 1024 FFT points, half-overlapping Hanning window). This initial analyses revealed that all detectable energy was found below 
$1.5 \mathrm{kHz}$, and both the in-air and underwater recordings were accordingly down-sampled to $6000 \mathrm{~Hz}$ for further analyses. The detailed spectral features of the recorded noise were examined by means of a power spectral density (PSD) analysis (4096 FFT points, half-overlapping Hanning window). Visual inspection of the spectrograms and PSD plots showed that detectable lower noise harmonics were evident above $50 \mathrm{~Hz}$ for the inair recordings of the Splashdrone and above $100 \mathrm{~Hz}$ for the Inspire, and that ambient noise was dominating frequencies below 160 and $100 \mathrm{~Hz}$ for the underwater recordings of the Splashdrone and the Inspire, respectively. Different filters were therefore used for the in-air and underwater recordings of the Splashdrone. A 4th-order Butterworth bandpass filter between 50 and $1500 \mathrm{~Hz}$ was used for the in-air recordings and between 160 and $1500 \mathrm{~Hz}$ for underwater recordings. All recordings from the Inspire were filtered using a 4th-order Butterworth filter between 100 and $1500 \mathrm{~Hz}$. We then computed the broad-band root-mean-square (rms) sound pressure level over a time windows of $20 \mathrm{~s}$ for both the filtered in-air and underwater recordings. The received levels in-air were then corrected for the flight altitude to provide estimates of the source level as back-calculated directly below the UAVs. To make the underwater UAV noise levels comparable to relevant measures of ambient noise and audiograms, we also computed the third-octave band levels using the Matlab script Filtbank (provided by Christophe Couvreur, Faculte Polytechnique de Mons, Belgium) implemented in MATLAB (Mathworks, Inc., 2013R) according to the ANSI standard S1.6-1984 (1984). All sound analyses were done using custom-programs in Matlab R2013b.

\section{RESULTS}

\section{In-Air Recordings}

Analyses of the in-air recordings revealed that the UAV noise was present in harmonic and subharmonic frequency bands. The fundamental frequency was found at $60 \mathrm{~Hz}$ for the Splashdrone and at $150 \mathrm{~Hz}$ for the Inspire (Figure 2), likely representing differences in rotor-revolutions. Most energy was found around $200 \mathrm{~Hz}$ for the Splashdrone and around $450 \mathrm{~Hz}$ for the Inspire. The bandpass filtered versions of the in-air recordings corrected for the $10 \mathrm{~m}$ transmission loss rendered mean broad rms source levels @ $1 \mathrm{~m}$ of $80 \mathrm{~dB}$ re $20 \mu \mathrm{Pa}$ for the Splashdrone and $81 \mathrm{~dB}$ re $20 \mu \mathrm{Pa}$ for the Inspire.

\section{Underwater Recordings}

The initial analysis of the underwater recordings showed that the UAV noise was only quantifiable above ambient noise when flown at 5 or $10 \mathrm{~m}$ above the sea surface. Accordingly, only the recordings from the two lowest flight altitudes were used in subsequent analyses. The three recordings yielded similar results for 5 and $10 \mathrm{~m}$ altitude between 91 and $97 \mathrm{~dB}$ re $1 \mu \mathrm{Pa}$ (rms) [mean of $95 \mathrm{~dB}$ re $1 \mu \mathrm{Pa}(\mathrm{rms})$ ] for the Splashdrone and of 98$102 \mathrm{~dB}$ re $1 \mu \mathrm{Pa}$ (rms) [mean of $101 \mathrm{~dB}$ re $1 \mu \mathrm{Pa}$ (rms)] for the Inspire (Figure 3). The corresponding mean third octave levels are plotted in Figure 4.

\section{DISCUSSION}

We recorded the noise levels of two UAVs commonly used in wildlife research to evaluate their potential for negative effects on marine mammals. In-air recordings showed that the noise levels produced by the two UAVs were within the noise-level range known to cause disturbance in some marine mammals, such as sea otters (Enhydra lutris) and pinnipeds, which either haul out or surface with their heads out of the water (Richardson et al., 1995). In line with that, UAVs have indeed been reported to have negative effects on pinnipeds whilst on land (Pomeroy et al., 2015; Smith et al., 2016). Thus, for low altitude UAV work focusing on marine mammals in-air, negative effects are likely to occur in some cases, and should be thoroughly addressed via dedicated impact studies. On the contrary, the in-water received noise levels at $1 \mathrm{~m}$ depth were uniformly low for UAVs flown at low altitudes ( 5 and $10 \mathrm{~m}$; Figure 3). Altitudes of 5 and $10 \mathrm{~m}$ may be used in the field for collection of exhalations (Acevedo-Whitehouse et al., 2010), but are in general well below more commonly used flight altitudes of $>30 \mathrm{~m}$ above marine mammals (Durban et al., 2015; Christiansen et al., 2016). As such, the following discussion on possible effects should be viewed as conservative for most UAV work given that the received levels assessed here are likely higher than what would normally be the case.

The large numerical value of approximately $40 \mathrm{~dB}$ difference between the broad-band received level at $1 \mathrm{~m}$ depth and the estimated received level at the water surface in-air (Figures 2, 3 ), pertains to the difference in reference values in-air and water and the large impedance difference between air and water by which most of the sound energy reflects off the water surface; very little energy of the in-air UAV noise couples into the water. The maximum broad-band received levels of some 95-100 dB re $1 \mu \mathrm{Pa}$ (rms) of the UAVs are comparable to what small research vessels would expose marine mammals to underwater at ranges between 100 and $300 \mathrm{~m}$ while moving slowly between 2 and 5 knots (Jensen et al., 2009). Such speeds and approach distances of small research vessels are common in field research and while commonality does not exclude negative effects on the study subjects, it highlights that noise from low flying UAVs are often likely to be masked by nearby vessels, possibly including the one carrying the UAV operator.

Received noise levels at or below $100 \mathrm{~dB}$ re $1 \mu \mathrm{Pa}$ (rms) are many orders of magnitude below those shown to cause direct damage on auditory systems or compromise physiology in marine mammals (Southall et al., 2007). The possible effects are therefore reduced to involving either behavioral disruptions or masking of pertinent auditory inputs from the environment. A prerequisite for behavioral effects is that the exposed animal can actually hear the noise, which in turn requires that the received noise levels are above both the hearing threshold and the ambient noise in the same set of auditory filters stimulated by the noise. In Figure 4 we have plotted the audiograms of the best hearing pinniped at low frequencies in water; the northern elephant seal (Mirounga angustirostris, Kastak and Schusterman, 1999), two toothed whales (Johnson, 1967; Kastelein et al., 2002), and a modeled fin whale (Balaenoptera physalus, Wenz, 1962; Cranford and Krysl, 2015). We have superimposed the third octave levels 

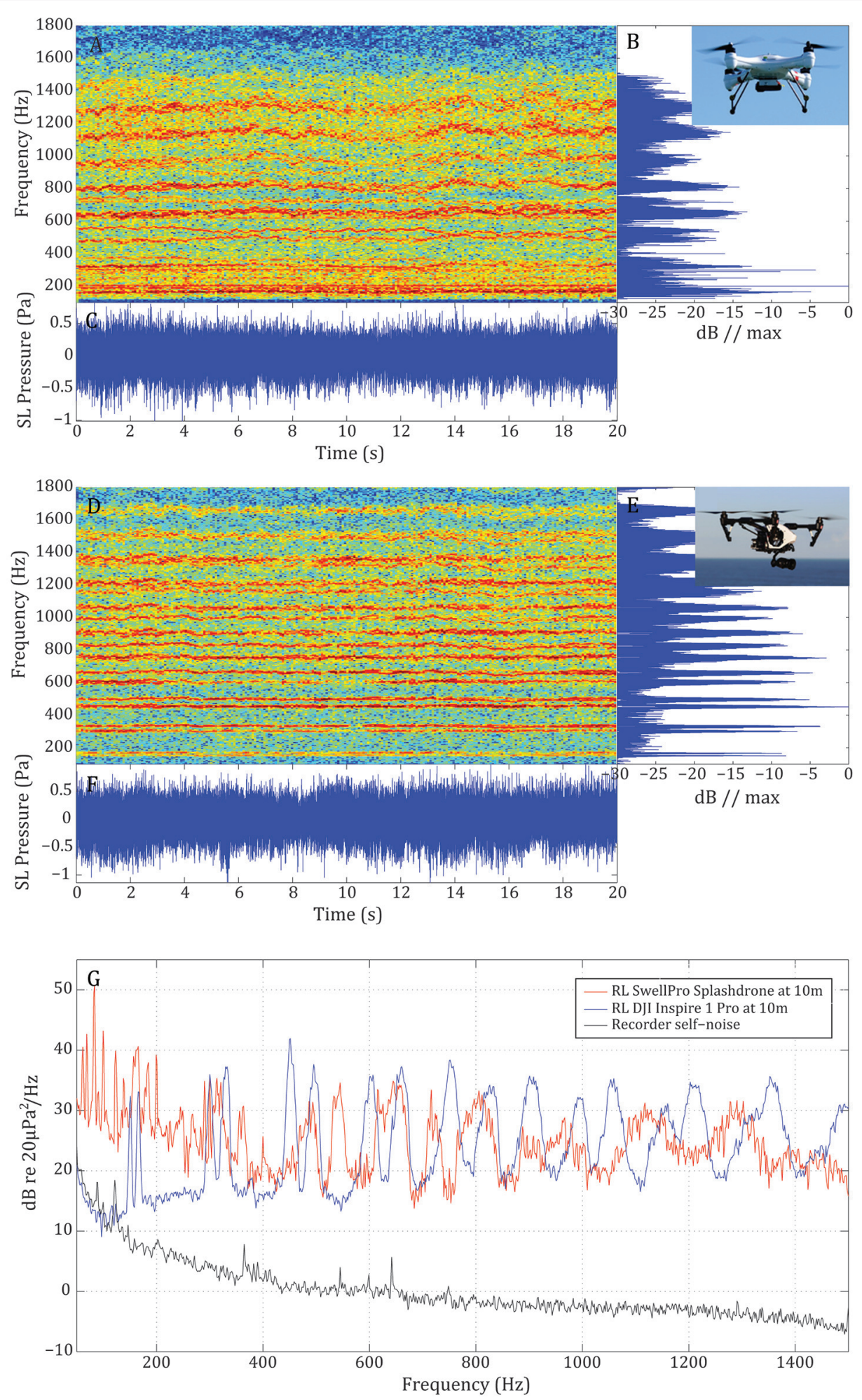

FIGURE 2 | Representation of the in-air recordings of the SwellPro Splashdrone and the DJI Inspire 1 Pro flying at $10 \mathrm{~m}$ altitude. (A,D) spectrograms of the received noise at water surface where specific harmonic and subharmonic frequency bands are visible. (B,E) relative power spectra of the received noise. (C,F) waveforms of the source level noise produced for each UAV. (G) Power spectral density of the received noise at $10 \mathrm{~m}$ for the SwellPro Splashdrone (red line) and the DJI Inspire 1 Pro (blue line). Self-noise of the recorder (black line) is shown for comparison. 

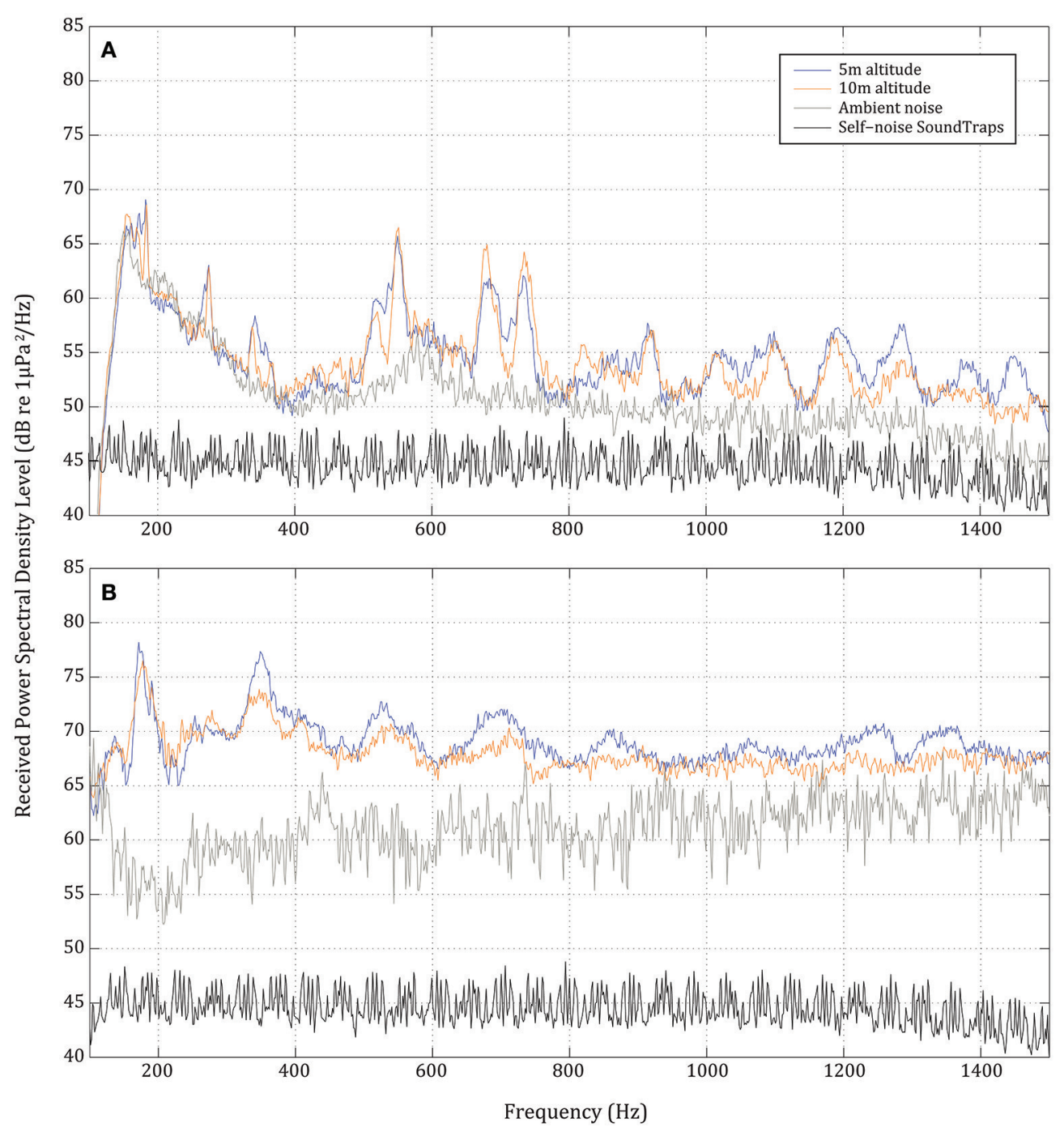

FIGURE 3 | Received power spectral density levels (RPSD dB re $1 \mu$ Pa RMS) of noise at $1 \mathrm{~m}$ depth when UAVs flying at 5 and $10 \mathrm{~m}$ (blue and orange lines, respectively). (A) SwellPro Splashdrone (broadband RMS received level of 88-89 and 87-88 dB re $1 \mu \mathrm{Pa}$ at 5 and $10 \mathrm{~m}$, respectively) and (B) DJI Inspire 1 Pro (broadband RMS received level of 101-102 and 100-101 dB re $1 \mu \mathrm{Pa}$ at 5 and $10 \mathrm{~m}$, respectively). The ambient noise in the experimental site (gray line) and the self-noise of the recorder (black line) is shown for comparison.

of the UAV noise (black dots) on the audiograms to compare the noise in frequency bands akin to those of the critical bands of marine mammals. The two toothed whales may at low ambient noise levels just be able to hear the Inspire, but likely not the Splashdrone. The modeled fin whale audiogram suggests that a fin whale should have a very hard time hearing either of the two UAVs. An audiogram has never been measured for any baleen whale, and as such, the modeled audiogram may not represent the true hearing capabilities of any baleen whale, including fin whales. If we therefore assume that evolution cannot drive the hearing threshold of any baleen whale below the lowest ambient noise levels, the Wenz 0 curve (Wenz, 1962) may be viewed as the best possible audiogram of any baleen whale. In that case, the UAV noise will be clearly audible to baleen whales under very low noise conditions. The same is true for the elephant seal that may hear the UAVs well at low ambient noise levels (Figure 4).
However, ambient noise levels are generally not low close to the surface or in coastal areas where much UAV work is conducted on marine mammals. To highlight the effect of average ambient noise levels, we have also plotted mean third octave levels from a suite of different habitats in Figure 4, showing that those levels in many cases are comparable to or higher than the UAV noise. Those masking effects are further compounded for logging animals by splashing sounds from breaking waves, rendering the UAV noise even more difficult to detect than depicted in Figure 4. Thus, it is clear that even though the audiograms for several marine mammals suggest that they may hear the UAV noise when close to the surface, the prevailing ambient noise will in many habitats effectively render the UAV noise inaudible via masking, as also evident by the poor signal to noise ratios we have faced during analysis in the present study. 


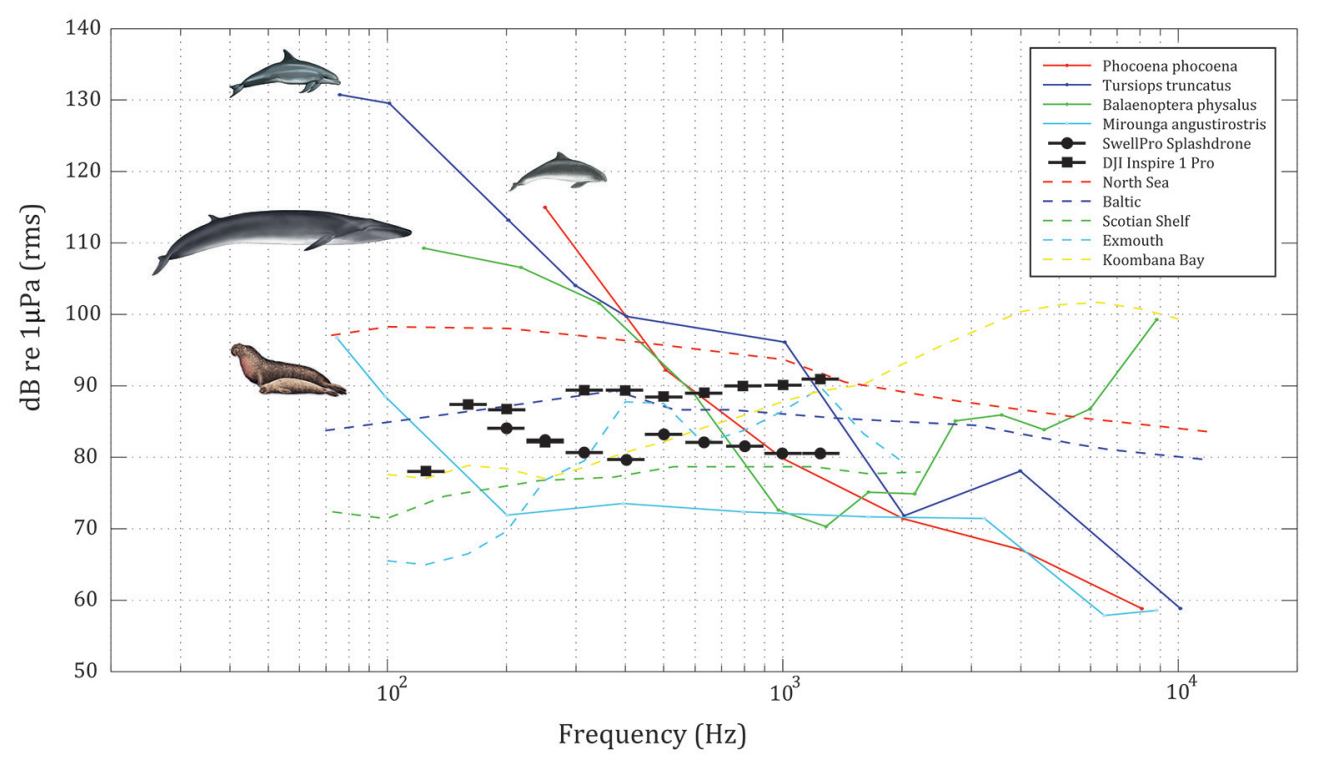

FIGURE 4 | Audiograms of a harbor porpoise (Phocoena phocoena, Kastelein et al., 2002), a bottlenose dolphin (Tursiops truncatus, Johnson, 1967), a northern elephant seal (Mirounga angustirostris, Kastak and Schusterman, 1999) and the predicted audiogram of a fin whale calf (Balaenoptera physalus, Cranford and Krysl, 2015). Ambient third-octave sound pressure levels (TOLs) in dB re $1 \mu \mathrm{Pa}$ RMS in five different shallow-water habitats: North Sea (Willie and Geyer, 1984), Baltic (Willie and Geyer, 1984), Scotian shelf (Piggott, 1964), Exmouth (Hermannsen et al. unpublished) and Koombana bay (Jensen et al., 2009). SwellPro Splashdrone and DJI Inspire 1 Pro received TOLs in $\mathrm{dB}$ re $1 \mu \mathrm{Pa}$ RMS at $1 \mathrm{~m}$ depth when UAVs hovering at $5 \mathrm{~m}$ altitude.

Finally, if marine mammals with good low frequency hearing are close to the surface in low ambient noise conditions and have a low flying UAV above them, there is no evidence to suggest that exposure levels below $100 \mathrm{~dB}$ re $1 \mu \mathrm{Pa}$ (rms) in water have led to any detectable behavioral disruptions in marine mammals (Southall et al., 2007). Opportunistic observations of humpback whales (Megaptera novaeangliae) and Southern right whales (Eubalaena australis) on their breeding grounds support that notion: During close up $(<10 \mathrm{~m})$ approaches with the same UAV models as in this study no behavioral responses of the animals toward the UAVs were detected (Christiansen et al., 2016). Other studies on cetaceans have reported on similar lack of behavioral responses of both toothed whales and baleen whales toward UAVs (Acevedo-Whitehouse et al., 2010; Durban et al., 2015; Koski et al., 2015). Sirenians too do not appear to be acoustically disturbed by UAVs, based on the lack of observed behavioral responses during UAV operations (Jones et al., 2006; Hodgson et al., 2013). In contrast, conventional aircrafts and helicopters with substantially higher source levels can elicit strong behavioral responses in cetaceans (Patenaude et al., 2002; Smultea et al., 2008). Bowhead (Balaena mysticetus) and beluga whales (Delphinapterus leucas) reacted to low flying $(<150 \mathrm{~m})$ helicopters during $26.3(5 / 19)$ and $50.0 \%$ (6/12) of overhead flights ( $<250 \mathrm{~m}$ lateral distance), respectively (Patenaude et al., 2002). Although responses to low flying $(<182 \mathrm{~m})$ fixed-wing aircrafts were fewer $(3.7(8 / 218)$ and $4.2 \%$ (14/336) of flights, respectively), they still occurred (Patenaude et al., 2002). So far no behavioral reactions toward UAVs have been recorded for marine mammals underwater. Hence, the acoustic effect of UAVs on marine mammals in water, even when flying $<10 \mathrm{~m}$ above the study animals, is likely to be absent or very small, and far less than that of conventional aircrafts, as long as the type of UAVs used generate noise at similar or lower levels than the types (Splashdrone and Inspire) used in this study (Jones et al., 2006; Acevedo-Whitehouse et al., 2010; Goebel et al., 2015; Moreland et al., 2015; Pomeroy et al., 2015).

With UAVs becoming an increasingly popular tool to study marine mammals, this study provides valuable information about the potential impacts of UAVs on the targeted animals. This information will be useful for wildlife managers and regulators when issuing permits and setting guidelines for UAV operations. However, it is important to highlight that many factors not investigated in this study are likely to affect the noise levels produced by UAVs. The noise produced by a multi-rotor UAV will depend on its propulsion system, electric motors, propellers, flight controller setup, frame, weight, speed, and how well the UAV has been balanced and calibrated. Further, the potential effect of UAVs on marine mammals will depend on the study species and the behavioral context of the animal at the time of flying (Smith et al., 2016). Further, Pomeroy et al. (2015) found that the reaction of pinnipeds to UAVs depended on their age, sex and biological state (i.e., breeding vs. molting). The noise produced by UAVs will also increase with increased wind speeds, since the engines will have to work harder to maintain the position of the UAV. However, increased wind speeds will also increase ambient noise levels, so that the perceived noise levels may be similar or even smaller than during calm weather conditions. We therefore recommend that future UAV studies, especially those involving more powerful UAVs than the one used in this study, carry out similar types of noise recordings as the one described in this study and compare them to the ambient noise levels in their study areas. Further, we recommend 
that behavioral impact studies are conducted on the study animals in conjunction with any research project on marine mammals involving UAVs, to test the assertions entertained in this paper and to ensure that any observer bias is known when using UAVs on wildlife. Finally, UAV operators also need to consider potential impact of their UAV on other wildlife than the targeted species, and take appropriate actions to minimize these.

We want to emphasize that this study was carried out under strict permitting conditions and that the pilot (F Christiansen) was trained and licensed to use UAVs for scientific purposes. With the use of recreational UAVs increasing rapidly around the world (Teal Group Corporation, 2011), regulators need to take a precautionary approach when setting up guidelines and regulations for the public, to minimize potential negative impacts from inexperienced and irresponsible operators.

\section{AUTHOR CONTRIBUTIONS}

Conceived and designed the experiments: FC, LB, and PM. Performed the experiments: FC, LB, and PM. Analyzed the data: LR and PM. Wrote the paper: FC, PM, LB, and LR.

\section{REFERENCES}

Acevedo-Whitehouse, K., Rocha-Gosselin, A., and Gendron, D. (2010). A novel non-invasive tool for disease surveillance of free-ranging whales and its relevance to conservation programs. Anim. Conserv. 13, 217-225. doi: 10.1111/j.1469-1795.2009.00326.x

Anderson, K., and Gaston, K. J. (2013). Lightweight unmanned aerial vehicles will revolutionize spatial ecology. Front. Ecol. Environ. 11, 138-146. doi: $10.1890 / 120150$

Brooke, S., Graham, D., Jacobs, T., Littnan, C., Manuel, M., and O'Conner, R. (2015). Testing marine conservation applications of unmanned aerial systems (UAS) in remote marine protected area. J. Unmanned Veh. Syst. 3, 237-251. doi: 10.1139/juvs-2015-0011

Carstensen, J., Henriksen, O. D., and Teilmann, J. (2006). Impacts of offshore wind farm construction on harbour porpoises: acoustic monitoring of echolocation activity using porpoise detectors (T-PODs). Mar. Ecol. Prog. Ser. 321, 295-308. doi: $10.3354 /$ meps 321295

Chabot, D., and Bird, D. M. (2015). Wildlife research and management methods in the 21st century: where do unmanned aircraft fit in? J. Unmanned Veh. Syst. 3 , 137-155. doi: 10.1139/juvs-2015-0021

Christiansen, F., Dujon, A. M., Sprogis, K. R., Arnould, J. P. Y., and Bejder, L. (2016). Noninvasive unmanned aerial vehicle provides estimates of the energetic cost of reproduction in humpback whales. Ecosphere 7:e01468. doi: $10.1002 /$ ecs2.1468

Cranford, T. W., and Krysl, P. (2015). Fin whale sound reception mechanisms: skull vibration enables low-frequency hearing. PLOS ONE 10:e0116222. doi: 10.1371/journal.pone.0116222

Durban, J. W., Fearnbach, H., Barrett-Lennard, L. G., Perryman, W. L., and Leroi, D. J. (2015). Photogrammetry of killer whales using a small hexacopter launched at sea. J. Unmanned Veh. Syst. 3, 131-135. doi: 10.1139/juvs-2015-0020

Goebel, M. E., Perryman, W. L., Hinke, J. T., Krause, D. J., Hann, N. A., Gardner, S., et al. (2015). A small unmanned aerial system for estimating abundance and size of Antarctic predators. Polar Biol. 38, 619-630. doi: 10.1007/s00300-014-1625-4

Goldbogen, J. A., Southall, B. L., DeRuiter, S. L., Calambokidis, J., Friedlaender, A. S., Hazen, E. L., et al. (2013). Blue whales respond to simulated mid-frequency military sonar. Proc. R. Soc. B 280:20130657. doi: 10.1098/rspb.2013.0657

Gordon, J., Gillespie, D., Potter, J., Frantzis, A., Simmonds, M. P., Swift, R., et al. (2003). A review of the effects of seismic surveys on marine mammals. Mar. Technol. Soc. J. 37, 16-34. doi: 10.4031/002533203787536998

\section{FUNDING}

This study was supported by the Murdoch University's Small Grants Scheme and the Sir Walter Murdoch Adjunct Professorial Award.

\section{ACKNOWLEDGMENTS}

We thank M. L. K. Nielsen, K. R. Sprogis, J. Totterdell (Marine Information and Research Group, Australia) and J. A. Tyne for assisting during the field trials. We thank J. N. Smith for technical assistance with the SoundTrap. We thank Global Unmanned Systems (http://www.gus-uav.com) and Victorian UAS Training (http://www.victorianuastraining.com. au) for UAV technical support and training. We thank Associate Editor R. Harcourt and two reviewers for their constructive comments which helped to improve this manuscript. The UAVs in this study were operated under a Remotely Piloted Aircraft System License (ARN: 837589) and two UAV Operator Certificates (CASA.UOC.0136 and CASA.UOC.1-YC6NP-03), in accordance with regulations by the Australian Civil Aviation Safety Authority (CASA).

Hermannsen, L., Beedholm, K., Tougaard, J., and Madsen, P. T. (2014). High frequency components of ship noise in shallow water with a discussion of implications for harbor porpoises (Phocoena phocoena). J. Acoust. Soc. Am. 136, 1640-1653. doi: 10.1121/1.4893908

Hodgson, A., Kelly, N., and Peel, D. (2013). Unmanned aerial vehicles (UAVs) for surveying Marine Fauna: a dugong case study. PLoS ONE 8:e79556. doi: 10.1371/journal.pone.0079556

Jensen, F. H., Bejder, L., Wahlberg, M., Aguilar Soto, N., Johnson, M., and Madsen, P. T. (2009). Vessel noise effects on delphinid communication. Mar. Ecol. Prog. Ser. 395, 161-175. doi: 10.3354/meps08204

Johnson, C. S. (1967). "Sound detection thresholds in marine mammals," in Marine Bioacoustics II, ed W. N. Tavolga (Oxford: Pergamon), 247-260.

Jones, G. P., Pearlstine, L. G., and Percival, H. F. (2006). An assessment of small unmanned aerial vehicles for wildlife research. Wildl. Soc. Bull. 34, 750-758. doi: 10.2193/0091-7648(2006)34[750:AAOSUA]2.0.CO;2

Kastak, D., and Schusterman, R. J. (1999). In-air and underwater hearing sensitivity of a northern elephant seal (Mirounga angustirostris). Can. J. Zool. 77, 1751-1758. doi: 10.1139/z99-151

Kastelein, R. A., Bunskoek, P., Hagedoorn, M., Au, W. W. L., and de Haan, D. (2002). Audiogram of a harbor porpoise (Phocoena phocoena) measured with narrow-band frequency modulated signals. J. Acoust. Soc. Am. 112, 334-344. doi: $10.1121 / 1.1480835$

Koh, L. P., and Wich, S. A. (2012). Dawn of drone ecology: low-cost autonomous aerial vehicles for conservation. Trop. Conserv. Sci. 5, 121-132. doi: 10.1177/194008291200500202

Koski, W. R., Gamage, G., Davis, A. R., Mathews, T., Leblanc, B., and Ferguson, S. H. (2015). Evaluation of UAS for photographic re-identification of bowhead whales, Balaena mysticetus. J. Unmanned Veh. Syst. 3, 22-29. doi: 10.1139/juvs-2014-0014

Linchant, J., Lisein, J., Semeki, J., Lejeune, P., and Vermeulen, C. (2015). Are unmanned aircraft systems (UASs) the future of wildlife monitoring? A review of accomplishments and challenges. Mamm. Rev. 45, 239-252. doi: 10.1111/mam.12046

Madsen, P. T., Wahlberg, M., Tougaard, J., Lucke, K., and Tyack, P. (2006). Wind turbine underwater noise and marine mammals: implications of current knowledge and data needs. Mar. Ecol. Prog. Ser. 309, 279-295. doi: $10.3354 / \mathrm{meps} 309279$

Miller, P. J. O., Biassoni, N., Samuels, A., and Tyack, P. L. (2000). Whale songs lengthen in response to sonar. Nature 405, 903. doi: 10.1038/350 16148 
Moreland, E. E., Cameron, M. F., Angliss, R. P., and Boveng, P. L. (2015). Evaluation of a ship-based unoccupied aircraft system (UAS) for surveys of spotted and ribbon seals in the Bering Sea pack ice. J. Unmanned Veh. Syst. 3, 114-122. doi: 10.1139/juvs-2015-0012

Nowacek, D. P., Christiansen, F., Bejder, L., Goldbogen, J. A., and Friedlaender, A. S. (2016). Studying cetacean behaviour: new technological approaches and conservation applications. Anim. Behav. 120, 235-244. doi: 10.1016/j.anbehav.2016.07.019

Nowacek, D. P., Thorne, L. H., Johnston, D. W., and Tyack, P. L. (2007). Responses of cetaceans to anthropogenic noise. Mamm. Rev. 37, 81-115. doi: 10.1111/j.1365-2907.2007.00104.x

NRC (2005). Marine Mammal Populations and Ocean Noise: Determining When Noise Causes Biologically Significant Effects. Washington, DC: The National Academies Press.

Ogden, L. E. (2013). Drone ecology. Bioscience 63:776. doi: 10.1093/bioscience/ 63.9.776

Patenaude, N. J., Richardson, W. J., Smultea, M. A., Koski, W. R., Miller, G. W., Würsig, B., et al. (2002). Aircraft sound and disturbance to bowhead and beluga whales during spring migration in the Alaskan Beaufort Sea. Mar. Mammal Sci. 18, 309-335. doi: 10.1111/j.1748-7692.2002.tb01040.x

Piggott, C. L. (1964). Ambient sea noise at low frequencies in shallow water of the Scotian Shelf. J. Acoust. Soc. Am. 36, 2152-2163. doi: 10.1121/1.1919337

Pirotta, E., Brookes, K. L., Graham, I. M., and Thompson, P. M. (2014). Variation in harbour porpoise activity in response to seismic survey noise. Biol. Lett. 10:20131090. doi: 10.1098/rsbl.2013.1090

Pomeroy, P., Connor, L. O., and Davies, P. (2015). Assessing use of and reaction to unmanned aerial systems in gray and harbor seals during breeding and molt in the UK. J. Unmanned Veh. Syst. 3, 102-113. doi: 10.1139/juvs-2015-0013

Richardson, W. J. Greene, C. R., Jr., Malme, C. I., and Thomson, D. H. (1995). Marine Mammals and Noise. San Diego, CA: Academic Press.

Rolland, R. M., Parks, S. E., Hunt, K. E., Castellote, M., Corkeron, P. J., Nowacek, D. P., et al. (2012). Evidence that ship noise increases stress in right whales. Proc. R. Soc. B 279, 2363-2368. doi: 10.1098/rspb.2011.2429

Smith, C. E., Sykora-Bodie, S. T., Bloodworth, B., Pack, S. M., Spradlin, T. R., and Leboeuf, N. R. (2016). Assessment of known impacts of unmanned aerial systems (UAS) on marine mammals: data gaps and recommendations for researchers in the United States. J. Unmanned Veh. Syst. 4, 1-14. doi: 10.1139/juvs-2015-0017
Smultea, M. A., Mobley, J. R. Jr., Fertl, D., and Fulling, G. L. (2008). An unusual reaction and other observations of sperm whales near fixed-wing aircraft. Gulf Caribb. Res. 20, 75-80. doi: 10.18785/gcr.2001.10

Southall, B. L., Bowles, A. E., Ellison, W. T., Finneran, J. J., Gentry, R. L., Greene, C. R. Jr., et al. (2007). Marine mammal noise exposure criteria: initial scientific recommendations. Aquat. Mamm. 33, 411-521. doi: 10.1578/AM.33.4.2007.411

Sweeney, K. L., Helker, V. T., Perryman, W. L., LeRoi, D. J., Fritz, L. W., Gelatt, T. S., et al. (2016). Flying beneath the clouds at the edge of the world: using a hexacopter to supplement abundance surveys of Steller sea lions (Eumetopias jubatus) in Alaska. J. Unmanned Veh. Syst. 4, 1-12. doi: 10.1139/juvs-2015-0010

Teal Group Corporation (2011). World Unmanned Aerial Vehicle Systems: Marke Profile and Forecast. Fairfax, VA: Report from the Teal Group Corporation.

Tougaard, J., Wright, A. J., and Madsen, P. T. (2015). Cetacean noise criteria revisited in the light of proposed exposure limits for harbour porpoises. Mar. Pollut. Bull. 90, 196-208. doi: 10.1016/j.marpolbul.2014.10.051

Tyack, P. (1998). "Acoustic communication under the sea” in Animal Acoustic Communication: Recent Technical Advances, eds S. L. Hopp, M. J. Owren, and C. S. Evans (Heidelberg: Springer-Verlag), 163-220.

Vas, E., Lescroël, A., Duriez, O., Boguszewski, G., and Grémillet, D. (2015). Approaching birds with drones: first experiments and ethical guidelines. Biol. Lett. 11:20140754. doi: 10.1098/rsbl.2014.0754

Wenz, G. M. (1962). Acoustic ambient noise in the ocean: spectra and sources. $J$. Acoust. Soc. Am. 34, 1936-1956. doi: 10.1121/1.1909155

Willie, P. C., and Geyer, D. (1984). Measurements on the origin of the winddependent ambient noise variability in shallow water. J. Acoust. Soc. Am. 75, 173-185. doi: 10.1121/1.390411

Conflict of Interest Statement: The authors declare that the research was conducted in the absence of any commercial or financial relationships that could be construed as a potential conflict of interest.

Copyright (c) 2016 Christiansen, Rojano-Doñate, Madsen and Bejder. This is an open-access article distributed under the terms of the Creative Commons Attribution License (CC BY). The use, distribution or reproduction in other forums is permitted, provided the original author(s) or licensor are credited and that the original publication in this journal is cited, in accordance with accepted academic practice. No use, distribution or reproduction is permitted which does not comply with these terms. 